IZA DP No. 10157

Wage Decompositions Using Panel Data Sample Selection Correction

Ronald L. Oaxaca

Chung Choe

August 2016

Forschungsinstitut zur Zukunft der Arbeit Institute for the Study of Labor 


\title{
Wage Decompositions Using Panel Data Sample Selection Correction
}

\author{
Ronald L. Oaxaca \\ University of Arizona \\ and IZA \\ Chung Choe \\ Hanyang University - ERICA Campus
}

Discussion Paper No. 10157

August 2016

IZA
P.O. Box 7240
53072 Bonn
Germany

Phone: +49-228-3894-0

Fax: +49-228-3894-180

E-mail: iza@iza.org

\begin{abstract}
Any opinions expressed here are those of the author(s) and not those of IZA. Research published in this series may include views on policy, but the institute itself takes no institutional policy positions. The IZA research network is committed to the IZA Guiding Principles of Research Integrity.

The Institute for the Study of Labor (IZA) in Bonn is a local and virtual international research center and a place of communication between science, politics and business. IZA is an independent nonprofit organization supported by Deutsche Post Foundation. The center is associated with the University of Bonn and offers a stimulating research environment through its international network, workshops and conferences, data service, project support, research visits and doctoral program. IZA engages in (i) original and internationally competitive research in all fields of labor economics, (ii) development of policy concepts, and (iii) dissemination of research results and concepts to the interested public.
\end{abstract}

IZA Discussion Papers often represent preliminary work and are circulated to encourage discussion. Citation of such a paper should account for its provisional character. A revised version may be available directly from the author. 
IZA Discussion Paper No. 10157

August 2016

\section{ABSTRACT \\ Wage Decompositions Using Panel Data
Sample Selection Correction}

This paper analyzes wage decomposition methodology in the context of panel data sample selection embedded in a correlated random effects setting. Identification issues unique to panel data are examined for their implications for wage decompositions. As an empirical example, we apply our methodology to German Socio-Economic Panel (GSOEP) data with which we investigate gender wage differentials in the German Labor Market. Our results highlight the sensitivity of inferences about potential discrimination to how elements of the panel data selection model are assigned to explained and unexplained components.

JEL Classification: J31, J71, C00

Keywords: decomposition, panel data, GSOEP, sample selection

Corresponding author:

Ronald Oaxaca

Department of Economics, Eller College of Management

University of Arizona

P.O. Box 210108

Tucson, AZ 85721-0108

USA

E-mail: rlo@email.arizona.edu 


\section{Introduction}

Since the seminal works by Oaxaca (1973) and Blinder (1973), numerous empirical studies have adopted the decomposition technique to quantify the unexplained part of wage differentials between groups, e.g. male vs. female, unionized vs. non-unionzed workers, workers in private vs public-sector, etc. As well documented in a comprehensive survey by Fortin et al. (2011), a large number of studies also aimed at suggesting alternative approaches to cope with methodological issues such as 1) the choice of omitted reference groups in detailed wage decompositions; 2) the choice of counterfactual reference parameters; 3) extensions to non-linear models; and 4) decompositions beyond sample means.

Identification of the discrimination-free wage structure is one of the key issues in decomposition analyses. While the coefficient estimates of male workers were suggested initially as the counterfactual reference parameters (Oaxaca, 1973), the male wage structure may not be appropriate for the counterfactual wage structure in the absence of labor market discrimination. Among other alternatives, Neumark (1988) proposed to use the coefficient estimates based on a pooled regression without group-specific intercepts. More recently, however, we still observe a debate on the ways to measure the unexplained gaps: pooled-sample vs. intercept-shift approaches (Elder et al., 2010; Lee, 2015).

Another source of ambiguity in wage decompositions is the lack of invariance with respect to the choice of left out reference groups when estimating the separate contributions of group differences in dummy variable coefficients to the unexplained wage gap (Oaxaca and Ransom, 1999). Solutions to this problem are found in Gardeazabal and Ugidos (2004) and Yun (2005). For further extensions, among others, the decomposition techniques are extended to the decomposition of the group differentials across 
the entire wage distribution (Machado and Mata, 2005) and to the applications for non-linear models (Bauer and Sinning, 2008).

Panel data models and selectivity correction models each present interesting complications for decomposition methodology. For panel data models, special considerations arise with respect to unobserved heterogeneity in the presence of repeated observations. In the case of the popularly used Heckman selection correction method (Heckman, 1979), there is inherent ambiguity about how to characterize group differences in a) selection equation parameters and b) covariances between selection equation errors and main (outcome) equation errors.

In Neuman and Oaxaca $(2003,2004)$, gender wage decompositions were examined in a cross-section setting in which Heckman selection models were used. A convenient, but in our view often a less than satisfactory, solution is to simply net out the selection terms from the observed wage gap. The resulting wage decomposition is identical in form to the conventional decomposition. The problem is that this decomposition describes an estimated counterfactual wage gap that is different from the one observed in the data. In this earlier work the authors developed 6 alternative decompositions of the selection terms corresponding to different assumptions about what is explained and what is unexplained. These involve constructing different counterfactuals regarding gender differences in parameters and covariates in the selection equation and gender differences in covariances between selection equation errors and the main equation errors. This work shows how dramatically inferences about discrimination change with different assumptions about the counterfactuals associated with the sample selection process.

The central idea of our paper is premised on the idea that the special circumstances surrounding sample selection panel data methods carry over to decomposition 
methodology. These special considerations have to be addressed when conducting wage decompositions using selection models estimated by panel data techniques. The contributions of the paper lie in showing how issues associated with correlated random effects carry over to wage decompositions based on panel data estimation methods. Among these issues is a unique decomposition identification problem that arises from the presence of time-invariant regressors combined with an empirical strategy of employing time-averages of the exogenous variables to estimate the selection mechanism and control for unobserved heterogeneity. We develop decomposition methods intended to accomodate sample selection and decomposition identification issues in panel data settings. For simplicity we confine ourselves to the normal distribution in a correlated random effects setting. We apply our methods to investigate the gender wage differentials in Germany using the well known German Socio-Economic Panel (GSOEP) data (1986-2011).

Given that many different longitudinal data sets are available across countries, we also expect that our paper can serve as a practical guide for researchers on the application of panel data selection methods developed in Wooldridge (1995, 2010). Moreover, our decomposition methods are readily generalizable to other types of wage differentials e.g. union, race, and more broadly to any sort of outcome differential.

\section{Methods: panel data decomposition}

\subsection{Wage Model}

Consider the following panel data model:

$$
y_{i t}=x_{i t} \beta+c_{i}+u_{i t}
$$

where $y_{i t}$ is some measure of wages, e.g. log wages, $x_{i t}$ is a $1 \times \mathrm{xK}$ vector of observations on the covariates, $\beta$ is the conforming $\mathrm{Kx} 1$ parameter vector, $c_{i}$ is unobserved 
heterogeneity, and $u_{i t}$ is a random error term. In the case of an unbalanced design and following Wooldridge (2010, p. 833-35), the conditional mean of $y_{i t}$ can be expressed as

$$
E\left(y_{i t} \mid x_{i t}, \bar{z}_{i}, s_{i t}=1\right)=x_{i t} \beta+\bar{z}_{i} \pi+\theta_{1} \lambda_{i t}+\theta_{2} d_{2 t} \lambda_{i t}+\ldots+\theta_{T} d_{T t} \lambda_{i t}
$$

where $s_{i t}=1\left(y_{i t}\right.$ observed $), \bar{z}_{i}$ is a $1 \mathrm{xJ}$ vector of individual time averages for all exogenous variables in the model including those in $x_{i t}$ and the wage equation exclusion restrictions $^{1}$, $\mathrm{J}$ represents the number of exogenous variables in the model, the $d_{j t}$ variables are period indicators, $T$ is the last possible time period in the data, and $\lambda_{i t}$ is the Inverse Mills Ratio (IMR) associated with labor force participation for individual $i$ in period $t$.

The IMR may be expressed as

$$
\lambda_{i t}=\frac{\phi\left(\bar{z}_{i} \gamma_{t}\right)}{\Phi\left(\bar{z}_{i} \gamma_{t}\right)}
$$

and the reduced form probit selection equation estimated for a particular year $t$ for the binary labor force participation variable $l_{i t}$ for $N_{t}$ cross-section units is given by

$$
\operatorname{prob}\left(l_{i t}=1 \mid \bar{z}_{i}\right)=\Phi\left(\bar{z}_{i} \gamma_{t}\right)
$$

where $\gamma_{t}$ is the conforming $\mathrm{Jx} 1$ parameter vector.

In practice one constructs the IMR variables from probit models that are estimated separately for each year. Accordingly, the predicted IMR for a given individual in a given year is calculated as

$$
\hat{\lambda}_{i t}=\frac{\phi\left(\bar{z}_{i} \hat{\gamma}_{t}\right)}{\Phi\left(\bar{z}_{i} \hat{\gamma}_{t}\right)}
$$

The resulting estimating equation is therefore expressed by

$$
y_{i t}=x_{i t} \beta+\bar{z}_{i} \pi+\theta_{1} \hat{\lambda}_{i t}+\theta_{2} d_{2 t} \hat{\lambda}_{i t}+\ldots+\theta_{T} d_{T t} \hat{\lambda}_{i t}+\text { error }
$$

\footnotetext{
${ }^{1}$ For each individual the elements of $\bar{z}_{i}$ in every period are calculated as the averages of the exogenous variables over all periods that the individual appears in the sample, not just the periods in which the individual is employed.
} 
A special case arises from the presence of time invariant regressors in $x_{i t}$. Without loss of generality, we will let $x_{1 i}=\bar{z}_{1 i}$ represent the vector of time invariant regressors common to $x_{i t}$ and $\bar{z}_{i}$, including the constant term. Therefore, the vector $x_{1 i}\left(\bar{z}_{1 i}\right)$ can appear only once for each cross-sectional unit. Consequently, the parameter vectors $\beta_{1}, \pi_{1}$ are not identified. Only their sum $\left(\beta_{1}+\pi_{1}\right)$ can be estimated in the selectivity corrected equation. As shown below, this identification issue impacts decompositions that asymmetrically treat gender differences in the $\beta$ 's and the $\pi$ 's and/or in the $x$ 's and the $z$ 's.

\subsection{Decomposition Methods}

Suppose the sample selected main equation is estimated separately for males and females by OLS:

$$
\begin{aligned}
& y_{m i t}=x_{m i t} \hat{\beta}_{m}+\bar{z}_{m i} \hat{\pi}_{m}+\hat{\theta}_{m 1} \hat{\lambda}_{m i t}+\hat{\theta}_{m 2} d_{2 t} \hat{\lambda}_{m i t}+\ldots+\hat{\theta}_{m T} d_{T_{t}} \hat{\lambda}_{m i t}+\text { error } \\
& y_{f i t}=x_{f i t} \hat{\beta}_{f}+\bar{z}_{f i} \hat{\pi}_{f}+\hat{\theta}_{f 1} \hat{\lambda}_{f i t}+\hat{\theta}_{f 2} d_{2 t} \hat{\lambda}_{f i t}+\ldots+\hat{\theta}_{f T} d_{T_{t}} \hat{\lambda}_{f i t}+\text { error } .
\end{aligned}
$$

At the overall wage sample mean (across all individuals and time periods in the wage sample), the estimated models can be expressed as

$$
\begin{gathered}
\ddot{y}_{m}=\ddot{x}_{m} \hat{\beta}_{m}+\ddot{z}_{m} \hat{\pi}_{m}+\hat{\theta}_{m 1} \ddot{\lambda}_{m}+\hat{\theta}_{m 2} \ddot{\lambda}_{m 2}+\ldots+\hat{\theta}_{m T} \ddot{\lambda}_{m T} \\
\ddot{y}_{f}=\ddot{x}_{f} \hat{\beta}_{f}+\ddot{z}_{f} \hat{\pi}_{f}+\hat{\theta}_{f 1} \ddot{\lambda}_{f}+\hat{\theta}_{f 2} \ddot{\lambda}_{f 2}+\ldots+\hat{\theta}_{f T} \ddot{\lambda}_{f T}, \\
\text { where } \ddot{y}=\frac{\sum_{i=1}^{N} \sum_{t=1}^{T_{e i}} y_{i t}}{\sum_{i=1}^{N} T_{e i}}, \ddot{x}=\frac{\sum_{i=1}^{N} \sum_{t=1}^{T_{e i}} x_{i t}}{\sum_{i=1}^{N} T_{e i}}, \ddot{z}=\frac{\sum_{i=1}^{N} T_{e i} \bar{z}_{i}}{\sum_{i=1}^{N} T_{e i}}, \ddot{\lambda}=\frac{\sum_{i=1}^{N} \sum_{t=1}^{T_{e i}} \hat{\lambda}_{i t}}{\sum_{i=1}^{N} T_{e i}}, \\
\ddot{\lambda}_{2}=\frac{\sum_{i=1}^{N} \sum_{t=1}^{T_{e i}} d_{2 t} \hat{\lambda}_{i t}}{\sum_{i=1}^{N} T_{e i}}=\frac{\sum_{i=1}^{N} \hat{\lambda}_{i 2}}{\sum_{i=1}^{N} T_{e i}}, \ldots, \ddot{\lambda}_{T}=\frac{\sum_{i=1}^{N} \sum_{t=1}^{T_{e i}} d_{T t} \hat{\lambda}_{i t}}{\sum_{i=1}^{N} T_{e i}}=\frac{\sum_{i=1}^{N} \hat{\lambda}_{i T}}{\sum_{i=1}^{N} T_{e i}}
\end{gathered}
$$

$\mathrm{N}$ is the number of individuals, and $T_{e i}$ is the number of times the $i$ th individual 
appears in the wage sample, i.e. is employed. ${ }^{2}$

When the male wage structure is the baseline, the decomposition at the overall mean is given by

$$
\begin{aligned}
\ddot{y}_{m}-\ddot{y}_{f} & =\left(\ddot{x}_{m}-\ddot{x}_{f}\right) \hat{\beta}_{m}+\left(\ddot{z}_{m}-\ddot{z}_{f}\right) \hat{\pi}_{m}+\left(\ddot{\lambda}_{m}-\ddot{\lambda}_{f}\right) \hat{\theta}_{m 1}+\left(\ddot{\lambda}_{m 2}-\ddot{\lambda}_{f 2}\right) \hat{\theta}_{m 2}+\ldots \\
& +\left(\ddot{\lambda}_{m T}-\ddot{\lambda}_{f T}\right) \hat{\theta}_{m T} \\
& +\ddot{x}_{f}\left(\hat{\beta}_{m}-\hat{\beta}_{f}\right)+\ddot{z}_{f}\left(\hat{\pi}_{m}-\hat{\pi}_{f}\right)+\ddot{\lambda}_{f}\left(\hat{\theta}_{m 1}-\hat{\theta}_{f 1}\right)+\ddot{\lambda}_{f 2}\left(\hat{\theta}_{m 2}-\hat{\theta}_{f 2}\right)+\ldots \\
& +\ddot{\lambda}_{f T}\left(\hat{\theta}_{m T}-\hat{\theta}_{f T}\right) .
\end{aligned}
$$

Differences in the mean IMR's can be further decomposed into gender differences in the probit parameters and gender differences in the probit regressors:

$$
\begin{gathered}
\ddot{\lambda}_{m}-\ddot{\lambda}_{f}=\left(\ddot{\lambda}_{m}-\ddot{\lambda}_{f}^{0}\right)+\left(\ddot{\lambda}_{f}^{0}-\ddot{\lambda}_{f}\right) \\
\ddot{\lambda}_{m 2}-\ddot{\lambda}_{f 2}=\left(\ddot{\lambda}_{m 2}-\ddot{\lambda}_{f 2}^{0}\right)+\left(\ddot{\lambda}_{f 2}^{0}-\ddot{\lambda}_{f 2}\right)
\end{gathered}
$$

$$
\ddot{\lambda}_{m T}-\ddot{\lambda}_{f T}=\left(\ddot{\lambda}_{m T}-\ddot{\lambda}_{f T}^{0}\right)+\left(\ddot{\lambda}_{f T}^{0}-\ddot{\lambda}_{f T}\right)
$$

where $\ddot{\lambda}_{f}^{0}=\frac{\sum_{i=1}^{N} \sum_{t=1}^{T_{f i}} \hat{\lambda}_{f i t}^{0}}{\sum_{i=1}^{N_{f}} T_{f i}}, \hat{\lambda}_{f i t}^{0}=\frac{\phi\left(\bar{z}_{f i} \hat{\gamma}_{m t}\right)}{\Phi\left(\bar{z}_{f i} \hat{\gamma}_{m t}\right)}, \ddot{\lambda}_{f 2}^{0}=\frac{\sum_{i=1}^{N_{f}} \hat{\lambda}_{f i 2}^{0}}{\sum_{i=1}^{N_{f}} T_{f i}}, \hat{\lambda}_{f i 2}^{0}=\frac{\phi\left(\bar{z}_{f i} \hat{\gamma}_{m 2}\right)}{\Phi\left(\bar{z}_{f i} \hat{\gamma}_{m 2}\right)}, \ldots$, $\hat{\lambda}_{f i T}^{0}=\frac{\phi\left(\bar{z}_{f i} \hat{\gamma}_{m T}\right)}{\Phi\left(\bar{z}_{f i} \hat{\gamma}_{m T}\right)}, \ddot{\lambda}_{f T}^{0}=\frac{\sum_{i=1}^{N_{f}} \hat{\lambda}_{f i T}^{0}}{\sum_{i=1}^{N_{f}} T_{f i}}$.

The $\ddot{\lambda}_{f}^{0}, \ddot{\lambda}_{f 2}^{0}, \ldots, \ddot{\lambda}_{f T}^{0}$ terms represent the evaluation of the IMR's for females using the estimated probit parameters for the males. Accordingly, the term $\left(\ddot{\lambda}_{m}-\ddot{\lambda}_{f}^{0}\right)$ measures how much of the gender difference in $\ddot{\lambda}_{m}-\ddot{\lambda}_{f}$ is attributable to gender differences

\footnotetext{
${ }^{2}$ For notational convenience, we suppress the gender group subscript.
} 
in the variables determining selection and $\left(\ddot{\lambda}_{f}^{0}-\ddot{\lambda}_{f}\right)$ measures how much of the gender difference arises from gender differences in the probit parameters in the selection equation. These interpretations carry over to decompositions of $\left(\ddot{\lambda}_{m 2}-\ddot{\lambda}_{f 2}\right), \ldots,\left(\ddot{\lambda}_{m T}-\ddot{\lambda}_{f T}\right)$. The more detailed decomposition becomes

$$
\begin{aligned}
\ddot{y}_{m}-\ddot{y}_{f} & =\left(\ddot{x}_{m}-\ddot{x}_{f}\right) \hat{\beta}_{m}+\left(\ddot{z}_{m}-\ddot{z}_{f}\right) \hat{\pi}_{m}+\left(\ddot{\lambda}_{m}-\ddot{\lambda}_{f}^{0}\right) \hat{\theta}_{m 1}+\left(\ddot{\lambda}_{f}^{0}-\ddot{\lambda}_{f}\right) \hat{\theta}_{m 1} \\
& +\left(\ddot{\lambda}_{m 2}-\ddot{\lambda}_{f 2}^{0}\right) \hat{\theta}_{m 2}+\left(\ddot{\lambda}_{f 2}^{0}-\ddot{\lambda}_{f 2}\right) \hat{\theta}_{m 2}+\ldots+\left(\ddot{\lambda}_{m T}-\ddot{\lambda}_{f T}^{0}\right) \hat{\theta}_{m T}+\left(\ddot{\lambda}_{f T}^{0}-\ddot{\lambda}_{f T}\right) \hat{\theta}_{m T} \\
& +\ddot{x}_{f}\left(\hat{\beta}_{m}-\hat{\beta}_{f}\right)+\ddot{z}_{f}\left(\hat{\pi}_{m}-\hat{\pi}_{f}\right)+\ddot{\lambda}_{f}\left(\hat{\theta}_{m 1}-\hat{\theta}_{f 1}\right)+\ddot{\lambda}_{f 2}\left(\hat{\theta}_{m 2}-\hat{\theta}_{f 2}\right)+\ldots \\
& +\ddot{\lambda}_{f T}\left(\hat{\theta}_{m T}-\hat{\theta}_{f T}\right) .
\end{aligned}
$$

There are of course any number of ways to combine the decomposition terms to reflect explained and unexplained (discrimination?) differences (for the cross-section case see Neuman and Oaxaca, 2003, 2004). Below, we consider eight alternative decomposition methods. In our view these alternatives span the most obvious (and potentially interesting) ways one would want to consider for allocating decomposition components to the categories of explained and unexplained. Each method is introduced by a succinct statement that captures the essence of the approach being taken.

\section{Method 1}

As a first approximation one can simply lump together all differences associated with gender differences in characteristics into the explained category and all differences associated with gender differences in parameters into the unexplained category:

$$
\ddot{y}_{m}-\ddot{y}_{f}=E_{1}+U_{1},
$$

where 


$$
\begin{aligned}
E_{1} & =\left(\ddot{x}_{m}-\ddot{x}_{f}\right) \hat{\beta}_{m}+\left(\ddot{z}_{m}-\ddot{z}_{f}\right) \hat{\pi}_{m}+\left(\ddot{\lambda}_{m}-\ddot{\lambda}_{f}^{0}\right) \hat{\theta}_{m 1}+\left(\ddot{\lambda}_{m 2}-\ddot{\lambda}_{f 2}^{0}\right) \hat{\theta}_{m 2}+\ldots+\left(\ddot{\lambda}_{m T}-\ddot{\lambda}_{f T}^{0}\right) \hat{\theta}_{m T}, \\
U_{1} & =\ddot{x}_{f}\left(\hat{\beta}_{m}-\hat{\beta}_{f}\right)+\ddot{z}_{f}\left(\hat{\pi}_{m}-\hat{\pi}_{f}\right)+\ddot{\lambda}_{f}\left(\hat{\theta}_{m 1}-\hat{\theta}_{f 1}\right)+\ddot{\lambda}_{f 2}\left(\hat{\theta}_{m 2}-\hat{\theta}_{f 2}\right)+\ldots+\ddot{\lambda}_{f T}\left(\hat{\theta}_{m T}-\hat{\theta}_{f T}\right) \\
& +\left(\ddot{\lambda}_{f}^{0}-\ddot{\lambda}_{f}\right) \hat{\theta}_{m 1}+\left(\ddot{\lambda}_{f 2}^{0}-\ddot{\lambda}_{f 2}\right) \hat{\theta}_{m 2}+\ldots+\left(\ddot{\lambda}_{f T}^{0}-\ddot{\lambda}_{f T}\right) \hat{\theta}_{m T} .
\end{aligned}
$$

\section{Method 2}

The second method treats gender differences in coefficients on the IMR's as explained or at least not discriminatory:

$$
\ddot{y}_{m}-\ddot{y}_{f}=E_{2}+U_{2},
$$

where

$$
\begin{aligned}
E_{2} & =\left(\ddot{x}_{m}-\ddot{x}_{f}\right) \hat{\beta}_{m}+\left(\ddot{z}_{m}-\ddot{z}_{f}\right) \hat{\pi}_{m}+\left(\ddot{\lambda}_{m}-\ddot{\lambda}_{f}^{0}\right) \hat{\theta}_{m 1}+\left(\ddot{\lambda}_{m 2}-\ddot{\lambda}_{f 2}^{0}\right) \hat{\theta}_{m 2}+\ldots+\left(\ddot{\lambda}_{m T}-\ddot{\lambda}_{f T}^{0}\right) \hat{\theta}_{m T} \\
& +\ddot{\lambda}_{f}\left(\hat{\theta}_{m 1}-\hat{\theta}_{f 1}\right)+\ddot{\lambda}_{f 2}\left(\hat{\theta}_{m 2}-\hat{\theta}_{f 2}\right)+\ldots+\ddot{\lambda}_{f T}\left(\hat{\theta}_{m T}-\hat{\theta}_{f T}\right), \\
U_{2} & =\ddot{x}_{f}\left(\hat{\beta}_{m}-\hat{\beta}_{f}\right)+\ddot{z}_{f}\left(\hat{\pi}_{m}-\hat{\pi}_{f}\right)+\left(\ddot{\lambda}_{f}^{0}-\ddot{\lambda}_{f}\right) \hat{\theta}_{m 1}+\left(\ddot{\lambda}_{f 2}^{0}-\ddot{\lambda}_{f 2}\right) \hat{\theta}_{m 2}+\ldots+\left(\ddot{\lambda}_{f T}^{0}-\ddot{\lambda}_{f T}\right) \hat{\theta}_{m T} .
\end{aligned}
$$

\section{Method 3}

A somewhat agnostic approach is to identify a separate selection effect that is not included in either the explained or the unexplained components of the decomposition.

$$
\ddot{y}_{m}-\ddot{y}_{f}=E_{3}+U_{3}+S_{3},
$$

where

$$
\begin{aligned}
& E_{3}=\left(\ddot{x}_{m}-\ddot{x}_{f}\right) \hat{\beta}_{m}+\left(\ddot{z}_{m}-\ddot{z}_{f}\right) \hat{\pi}_{m}+\left(\ddot{\lambda}_{m}-\ddot{\lambda}_{f}^{0}\right) \hat{\theta}_{m 1}+\left(\ddot{\lambda}_{m 2}-\ddot{\lambda}_{f 2}^{0}\right) \hat{\theta}_{m 2}+\ldots+\left(\ddot{\lambda}_{m T}-\ddot{\lambda}_{f T}^{0}\right) \hat{\theta}_{m T} \\
& U_{3}=\ddot{x}_{f}\left(\hat{\beta}_{m}-\hat{\beta}_{f}\right)+\ddot{z}_{f}\left(\hat{\pi}_{m}-\hat{\pi}_{f}\right)+\left(\ddot{\lambda}_{f}^{0}-\ddot{\lambda}_{f}\right) \hat{\theta}_{m 1}+\left(\ddot{\lambda}_{f 2}^{0}-\ddot{\lambda}_{f 2}\right) \hat{\theta}_{m 2}+\ldots+\left(\ddot{\lambda}_{f T}^{0}-\ddot{\lambda}_{f T}\right) \hat{\theta}_{m T} \\
& S_{3}=\ddot{\lambda}_{f}\left(\hat{\theta}_{m 1}-\hat{\theta}_{f 1}\right)+\ddot{\lambda}_{f 2}\left(\hat{\theta}_{m 2}-\hat{\theta}_{f 2}\right)+\ldots+\ddot{\lambda}_{f T}\left(\hat{\theta}_{m T}-\hat{\theta}_{f T}\right)
\end{aligned}
$$


The selectivity term $S_{3}$ arises solely from gender differences in the IMR coefficients.

\section{Method 4}

A more agnostic approach is to lump together all gender differences in the IMRs and IMR coefficients as selection effects. This approach confines the explained and unexplained components to a) gender differences in both the time varying covariates and the time-averaged means for the non IMR terms, and b) gender differences in the coefficients on the time varying covariates and the time-averaged means for the non IMR terms.

$$
\ddot{y}_{m}-\ddot{y}_{f}=E_{4}+U_{4}+S_{4}
$$

where

$$
\begin{aligned}
& E_{4}=\left(\ddot{x}_{m}-\ddot{x}_{f}\right) \hat{\beta}_{m}+\left(\ddot{z}_{m}-\ddot{z}_{f}\right) \hat{\pi}_{m} \\
& U_{4}=\ddot{x}_{f}\left(\hat{\beta}_{m}-\hat{\beta}_{f}\right)+\ddot{z}_{f}\left(\hat{\pi}_{m}-\hat{\pi}_{f}\right) \\
& S_{4}=\left(\hat{\theta}_{m 1} \ddot{\lambda}_{m}+\hat{\theta}_{m 2} \ddot{\lambda}_{m 2}+\ldots+\hat{\theta}_{m T} \ddot{\lambda}_{m T}\right)-\left(\hat{\theta}_{f 1} \ddot{\lambda}_{f}+\hat{\theta}_{f 2} \ddot{\lambda}_{f 2}+\ldots+\hat{\theta}_{f T} \ddot{\lambda}_{f T}\right) .
\end{aligned}
$$

\section{Method 5}

A fifth variant on our decomposition methodology regards the following elements as explained: all gender differences in the $\ddot{z}$ time averaged variables, their wage effects $\pi$, the $\ddot{x}$ regressors, and gender differences in the IMR coefficients. The resulting decomposition may be expressed as

$$
\ddot{y}_{m}-\ddot{y}_{f}=E_{5}+U_{5},
$$

where 


$$
\begin{aligned}
E_{5} & =\left(\ddot{x}_{m}-\ddot{x}_{f}\right) \hat{\beta}_{m}+\left(\ddot{z}_{m} \hat{\pi}_{m}-\ddot{z}_{f} \hat{\pi}_{f}\right)+\left(\ddot{\lambda}_{m}-\ddot{\lambda}_{f}^{0}\right) \hat{\theta}_{m 1}+\left(\ddot{\lambda}_{m 2}-\ddot{\lambda}_{f 2}^{0}\right) \hat{\theta}_{m 2}+\ldots+\left(\ddot{\lambda}_{m T}-\ddot{\lambda}_{f T}^{0}\right) \hat{\theta}_{m T} \\
& +\ddot{\lambda}_{f}\left(\hat{\theta}_{m 1}-\hat{\theta}_{f 1}\right)+\ddot{\lambda}_{f 2}\left(\hat{\theta}_{m 2}-\hat{\theta}_{f 2}\right)+\ldots+\ddot{\lambda}_{f T}\left(\hat{\theta}_{m T}-\hat{\theta}_{f T}\right), \\
U_{5} & =\ddot{x}_{f}\left(\hat{\beta}_{m}-\hat{\beta}_{f}\right)+\left(\ddot{\lambda}_{f}^{0}-\ddot{\lambda}_{f}\right) \hat{\theta}_{m 1}+\left(\ddot{\lambda}_{f 2}^{0}-\ddot{\lambda}_{f 2}\right) \hat{\theta}_{m 2}+\ldots+\left(\ddot{\lambda}_{f T}^{0}-\ddot{\lambda}_{f T}\right) \hat{\theta}_{m T} .
\end{aligned}
$$

This decomposition method eliminates the selection effect as a separate component in the decomposition and treats gender differences in the parameters of the probit selection equations as unexplained. It imposes the assumption that gender differences in unobserved heterogeneity as captured by $\ddot{z}_{m} \hat{\pi}_{m}-\ddot{z}_{f} \hat{\pi}_{f}$ are conceptually no different than the explained effects of gender differences in the observed characteristics, $\left(\ddot{x}_{m}-\ddot{x}_{f}\right) \hat{\beta}_{m}$

Note that Method 5 is a decomposition that treats gender differences in the $\beta$ 's and the $\pi$ 's asymmetrically. This asymmetry arises because gender differences in the $\beta$ parameters are included in the unexplained gap while gender differences in the $\pi$ parameters are assigned to the explained gap. Without identifying restrictions in the presence of time-invariant regressors appearing in $x_{i t}$, one cannot calculate the decomposition components $\left(\ddot{x}_{m 1}-\ddot{x}_{f 1}\right) \hat{\beta}_{m 1}, \ddot{x}_{f 1}\left(\hat{\beta}_{m 1}-\hat{\beta}_{f 1}\right)$, and $\ddot{z}_{m 1} \hat{\pi}_{m 1}-\ddot{z}_{f 1} \hat{\pi}_{f 1}$.

In general we cannot anticipate what, if any, identifying restrictions would be justified in a panel data decomposition analysis. Nevertheless, two normalization restrictions are worth considering. The normalization $\pi_{1}=0$ would allocate $\left(\ddot{x}_{m 1}-\ddot{x}_{f 1}\right) \hat{\beta}_{m 1}$ to $E_{5}$ and $\ddot{x}_{f 1}\left(\hat{\beta}_{m 1}-\hat{\beta}_{f 1}\right)$ to $U_{5}$. We refer to this variant as Method 5a. Alternatively, the normalization $\beta_{1}=0$ would allocate $\ddot{z}_{m 1} \hat{\pi}_{m 1}-\ddot{z}_{f 1} \hat{\pi}_{f 1}$ to $E_{5}$. This variant is Method 5b. With these two normalizations it is the case that $\hat{\beta}_{j 1}\left|\left(\pi_{j 1}=0\right)=\hat{\pi}_{j 1}\right|\left(\beta_{j 1}=0\right)$ and $\ddot{x}_{j 1}=\ddot{z}_{j 1}$, for $j=m, f$.

\section{Method 6}


Another decomposition approach is to treat gender differences in the $\ddot{z}$ time averaged variables entirely as part of the selection mechanism on the assumption that unobserved heterogeneity is inextricably bound up with selection:

$$
\ddot{y}_{m}-\ddot{y}_{f}=E_{6}+U_{6}+S_{6},
$$

where

$$
\begin{aligned}
E_{6} & =\left(\ddot{x}_{m}-\ddot{x}_{f}\right) \hat{\beta}_{m}, \\
U_{6} & =\ddot{x}_{f}\left(\hat{\beta}_{m}-\hat{\beta}_{f}\right), \\
S_{6} & =\left(\ddot{z}_{m} \hat{\pi}_{m}-\ddot{z}_{f} \hat{\pi}_{f}\right)+\left(\hat{\theta}_{m 1} \ddot{\lambda}_{m}+\hat{\theta}_{m 2} \ddot{\lambda}_{m 2}+\ldots+\hat{\theta}_{m T} \ddot{\lambda}_{m T}\right)-\left(\hat{\theta}_{f 1} \ddot{\lambda}_{f}+\hat{\theta}_{f 2} \ddot{\lambda}_{f 2}+\ldots+\hat{\theta}_{f T} \ddot{\lambda}_{f T}\right) .
\end{aligned}
$$

Because all of the gender differences in the selection terms are lumped together and included in the selection component, this methodology confines the explained and unexplained components of the decomposition to gender differences in the $x_{i t}$ covariates and gender differences in the $\beta$ coefficients on the $x_{i t}$ covariates, respectively.

Note that Method 6 is a decomposition that asymmetrically treats gender differences in the $\beta$ 's and the $\pi$ 's and in the $x$ 's and $z$ 's. The asymmetry here arises because a) the explained gap includes gender differences in the $x$ 's but excludes differences in the $z$ 's, and b) the unexplained gap includes gender differences in the $\beta$ parameters but excludes gender differences in the $\pi$ parameters. Consequently, the presence of time invariant regressors in $x_{i t}$ introduces identification issues in the decomposition analysis.

Again without identifying restrictions, one cannot in general calculate the decomposition components $\left(\ddot{x}_{m 1}-\ddot{x}_{f 1}\right) \hat{\beta}_{m 1}, \ddot{x}_{f 1}\left(\hat{\beta}_{m 1}-\hat{\beta}_{f 1}\right)$, and $\ddot{z}_{m 1} \hat{\pi}_{m 1}-\ddot{z}_{f 1} \hat{\pi}_{f 1}$. Similar to Method 5, the normalization $\pi_{1}=0$ allocates $\left(\ddot{x}_{m 1}-\ddot{x}_{f 1}\right) \hat{\beta}_{m 1}$ to $E_{6}$ and $\ddot{x}_{f 1}\left(\hat{\beta}_{m 1}-\hat{\beta}_{f 1}\right)$ to $U_{6}$. This decomposition is referred to as Method 6 a. On the other hand, the normalization $\beta_{1}=0$ allocates $\ddot{z}_{m 1} \hat{\pi}_{m 1}-\ddot{z}_{f 1} \hat{\pi}_{f 1}$ to $S_{6}$. We refer to this decomposition as 
Method 6b.

\section{Data and Summary Statistics}

The estimation of our model is carried out using data from the German Socio-Economic Panel (G-SOEP). The survey is a continuous series of national longitudinal data that was started in 1984. Approximately 11,000 private households are randomly drawn from the Federal Republic of Germany. The survey included a sample of Eastern German residents since 1990. Individuals are followed over time through an annual questionnaire on household composition, employment, occupations, earnings, health and satisfaction indicators.

Our sample is restricted to prime age working persons (age 18 to 65) in Western Germany, who are not serving in the armed forces and are not self-employed. We also exclude persons with missing data for any variables used in the empirical analyses. The final samples include 112,711 men (85,928 employed) and 124,059 women (69,476 employed) over the period 1986-2011.

In Table 1 we report the summary statistics on human capital and job characteristics, including immigration status and information on the years in Germany since migration. Predictably, males exhibit higher wage rates, experience, and a more favorable occupational distribution. Males are also slightly more highly educated. The hourly wage is calculated as monthly earnings divided by the number of monthly working hours. Monthly working hours are estimated as weekly working hours multiplied by 4.33 . The mean wage of male workers is $30.8 \%$ higher than the mean wage of female workers (€16.32 versus $€ 12.47$ ). Of course, between-group differences in job and productivity-related characteristics can explain a portion of the wage differences between male and female workers. For instance, men are more likely to obtain higher 
education, have much longer job tenure or are more likely to have managerial or professional positions. Males are more likely to be immigrants and conditional upon being immigrants, have lived in Germany about 8 to 9 months longer than female immigrants. Women are more likely to work in the service or trade sector while men are more likely to work in the manufacturing or construction sector.

\section{Results}

\subsection{Wage Equations by Gender}

The estimated $(\log )$ wage equations are reported in Table 2. The variables listed under Time varying covariates are the time varying regressors that appear in the vector $x_{i t}$. On the other hand, the variables listed under Time averaged means are the regressors appearing in the vector $\bar{z}_{i}$. Among these variables, those designated with an '(m)' are time averages of the time varying covariates in $x_{i t}$, the time invariant regressors $x_{1 i}=\bar{z}_{1 i}$ appearing in $x_{i t}$, and the time varying wage equation exclusion restrictions. ${ }^{3}$ The usual concavity in work experience is evident as well as the expected returns to education and occupational ordering. Wage rates are lower for immigrants, especially among males. Years since migration have no independent effect on the wage rates of males but do reduce the migration wage penalty for female immigrants. The nonstandard elements of the wage equations arise from the yearly IMR's and the time averaged means of the time-varying covariates. Interestingly, the selection results suggest a negative selection into the labor force, especially among males.

\subsection{Decomposition of Wage Differentials}

Table 3 reports the results of eight alternative decomposition methods. The overall, unadjusted gender wage differential across all individuals and time periods is 0.277 . As

\footnotetext{
${ }^{3}$ The exclusion restrictions are age, age squared, married, and children under 18.
} 
was the case in Oaxaca and Neuman (2004), there is large variation in the magnitudes of the decomposition components. These differences arise from how gender differences in the components of the selectivity term are allocated.

We first examine Methods 1,2, 5a, and 5b for which all of the selectivity terms are allocated to either the explained or the unexplained gaps, leaving no pure selectivity component in the decomposition. The two alternative normalizations for Method 5 yielded very nearly identical results. Method 2 yields the smallest positive estimate of the explained gap at 0.066 or $24 \%$ of the overall wage gap. Recall that this method simply aggregated all gender differences in characteristics and gender differences in coefficients on the IMR's into the explained gap while aggregating all other gender differences in parameters into the unexplained gap.

Methods 1, 5a, and 5b produced very nearly the same decompositions. The estimated explained gaps are respectively 0.107 (39\%), 0.118 (43\%), and $0.115(41 \%)$. Accordingly, the estimated unexplained gaps are 0.170 (61\%), 0.159 (57\%), and 0.163 (59\%). These three methods treat gender differences in the IMR coefficients $\left(\theta^{\prime} s\right)$ as explained but they differ from Method 2 in that the latter treats only the gender differences in the time-averaged means $\left(\bar{z}_{i}\right)$ as explained. In addition Methods 5 a and 5b treat gender differences in the coefficients $\left(\pi^{\prime} s\right)$ on the time-averaged means as explained.

Methods 3, 4, 6a, and 6b all include a separate selectivity component in the decomposition. As was the case for Methods $5 \mathrm{a}$ and 5b, the two alternative normalizations corresponding to Methods $6 \mathrm{a}$ and $6 \mathrm{~b}$ yielded very nearly identical results. Method 3 yields the largest positive explained gap which is calculated identically to the explained gap associated with Method 1, i.e. 0.107 (39\%). Method 3 also yields a sizable unexplained gap which is constructed identically to the unexplained gap from Method 
2, i.e. $0.212(76 \%)$. The difference here is that Method 3 allocates gender differences in the IMR coefficients to a separate selectivity component of the decomposition. On the other hand Method 4 places all gender differences associated with the IMR terms in a separate selection term in the decomposition while Methods $6 \mathrm{a}$ and $6 \mathrm{~b}$ augment the selection term by counting all gender differences associated with the time-averaged means as part of the selection process.

Selection for the most part has only a modest effect on the gender wage gap. In the cases of Methods 3 and 4, selection has a modest narrowing effect on the wage at $-0.041(-15 \%)$ and $-0.024(9 \%)$, respectively. Whereas for both Methods $6 \mathrm{a}$ and $6 \mathrm{~b}$, the selection effect modestly increases the gender wage gap at $0.059(21 \%)$.

Methods 4, 6a, and 6b yielded similar explained gaps of 0.087 (31\%), 0.056 (20\%), and $0.053(19 \%)$, respectively. The unexplained decomposition components were also similar for Methods 4, 6a, and 6b corresponding to to fairly substantial magnitudes of $0.214(77 \%), 0.162(58 \%)$, and $0.165(60 \%)$, respectively.

\section{Concluding Remarks}

The diversity of results that are produced from our eight alternative panel data wage decompositions is to be expected given the seemingly endless number of ways in which one can group decomposition components, conditional upon a given counterfactual. Our selection of these particular decompositions was guided by the desire to concentrate on the most obvious and salient features one would look for in a panel data setting with selectivity correction. We use the estimated parameters for males to construct our counterfactuals. One can of course alternatively use the estimated parameters for females or from a generalized decomposition methodology. What can be regarded as "best practice" in this setting is for the most part highly subjective. 
Arguably, the most important factor to consider is what is the objective of the decomposition in the first place. When one seeks to identify the unexplained gap as discrimination, decomposition methodology is at its most equivocal point. For one thing a researcher has to be quite confident that the model is correctly specified and that the $\beta$ coefficients on the time-varying covariates should be identical for males and females in the absence of discrimination. If this were indeed the case, then all eight methods include gender differences in the $\beta$ coefficients in the unexplained gap. Conditional on these beliefs about the true $\beta^{\prime} s$, it is probably not too great a leap to then assume that any gender difference in the returns $\left(\pi^{\prime} s\right)$ to the time averaged covariates $\left(z^{\prime} s\right)$ are discriminatory. This step rules out Methods 5 ('a' and 'b') and 6 ('a' and 'b') which are potentially susceptible to identification problems anyway, and rules in Methods $1-4$.

It is difficult to imagine broad support for the argument that gender differences in the probit selection equation parameters should be treated as discriminatory. If one takes this position, then only Method 4 survives. This method suggests that selection narrows the observed gender wage gap in our data by $-9 \%$. In this decomposition endowment effects favor men by about $31 \%$ of the observed gender wage differential. Men are also estimated to receive a major wage premium accounting for $77 \%$ of the observed wage differential.

If one is simply interested in a less restrictive exercise of estimating how much of the $(\log )$ wage differential arises from parameter differences versus endowment effects, Method 1 would be appropriate. However, the empirical model we estimate corrects for sample selection so it might make sense to isolate the effects of selection in the decomposition exercise. The least committal way (with respect to parsing out the unexplained gap) in which to estimate the effects of selection on the wage gap is 
either with Method 4 or 6 ('a' and 'b'). Because of the panel nature of the data with sample selection, the time-averaged regressors are intended to control for unobserved heterogeneity and the selection process. Accordingly, Methods $6 \mathrm{a}$ and $\mathrm{b}$ would be the appropriate approach to use in this context if identification is not an issue or if the existence of an identification problem could be managed by plausible restrictions.

Regardless of how one might ultimately choose to allocate components of the selection terms, the presence of a separate selection component in a decomposition can be informative about the sources of gender wage gaps. In our example, the evidence consistently reveals modest effects of sample selection on observed gender wage gaps. Methods 3 and 4 suggest selection of women into the workforce with higher earnings capacities. On the other hand Methods $6 \mathrm{a}$ and $6 \mathrm{~b}$ imply selection of women into the work force with lower earnings capacities.

If one were not interested in conducting decompositions, the presence of timeinvariant regressors would be fairly benign. In estimating wage equations one would estimate a single parameter for each time-invariant/time averaged mean regressor. Practically speaking, whether each of these parameters is viewed as the sum of two parameters or a single parameter identified off of a ' 0 ' restriction would not be all that important. As we have shown, from the standpoint of conducting decompositions, the identification issue only matters when it asymmetrically affects the allocation of decomposition components to explained and unexplained categories.

Although we use the GSOEP data set for our example because it is well known internationally, our methodology can be applied to the Korean Labor \& Income Panel Study (KLIPS) which is well known to Korean researchers. 


\section{References}

Bauer, T. and Sinning, M. (2008). An extension of the Blinder? Oaxaca decomposition to nonlinear models. AStA Advances in Statistical Analysis, 92(2):197-206.

Blinder, A. (1973). Wage discrimination: Reduced form and structural estimates. Journal of Human Resources, 8:436-455.

Elder, T. E., Goddeeris, J. H., and Haider, S. J. (2010). Unexplained gaps and OaxacaBlinder decompositions. Labour Economics, 17(1):284-290.

Fortin, N., Lemieux, T., and Firpo, S. (2011). Decomposition methods. In Ashenfelter, O. and Card, D., editors, Handbook of Labor Economics, volume 4A, pages 1-102. North-Holland, Amsterdam.

Gardeazabal, J. and Ugidos, A. (2004). More on Identification in Detailed Wage Decompositions. The Review of Economics and Statistics, 86(4):1034-1036.

Heckman, J. J. (1979). Sample Selection Bias as a Specification Error. Econometrica, 47(1):153-61.

Lee, M.-J. (2015). Reference parameters in Blinder-Oaxaca decomposition: Pooledsample versus intercept-shift approaches. Journal of Economic Inequality, 13(1):6982.

Machado, J. A. F. and Mata, J. (2005). Counterfactual decomposition of changes in wage distributions using quantile regression. Journal of Applied Econometrics, 20:445-465.

Neuman, S. and Oaxaca, R. L. (2003). Gender vs ethnic wage differentials among professionals: Evidence from israel. Annales d'Economie et de Statistique, (71$72): 12$. 
Neuman, S. and Oaxaca, R. L. (2004). Wage decompositions with selectivity-corrected wage equations: A methodological note. Journal of Economic Inequality, 2(1):3-10.

Neumark, D. (1988). Employers' discriminatory behavior and the estimation of wage discrimination. Journal of Human Resources, 23(3):279-295.

Oaxaca, R. (1973). Male-female wage differentials in urban labor markets. International Economic Review, 14(3):693-709.

Oaxaca, R. L. and Ransom, M. R. (1999). Identification in Detailed Wage Decompositions. The Review of Economics and Statistics, 81(1):154-157.

Wooldridge, J. M. (1995). Selection corrections for panel data models under conditional mean independence assumptions. Journal of Econometrics, 68(1):115-132.

Wooldridge, J. M. (2010). Econometric Analysis of Cross Section and Panel Data. The MIT Press, 2nd edition edition.

Yun, M.-S. (2005). A Simple Solution to the Identification Problem in Detailed Wage Decompositions. Economic Inquiry, 43(4):766-772. 
Table 1: Sample characteristics

\begin{tabular}{|c|c|c|c|c|}
\hline & \multicolumn{2}{|c|}{ Male } & \multicolumn{2}{|c|}{ Female } \\
\hline & Mean & STD & Mean & STD \\
\hline Hourly wage & 16.32 & 9.54 & 12.47 & 7.93 \\
\hline Log of hourly wage & 2.66 & 0.52 & 2.39 & 0.52 \\
\hline Exp & 18.42 & 11.83 & 15.16 & 10.55 \\
\hline Less than primary & 0.03 & 0.18 & 0.03 & 0.17 \\
\hline Primary & 0.16 & 0.37 & 0.19 & 0.39 \\
\hline Middle Vocational (ref) & 0.48 & 0.50 & 0.49 & 0.50 \\
\hline Vocational Plus Abi & 0.06 & 0.23 & 0.08 & 0.27 \\
\hline Higher Vocational & 0.08 & 0.28 & 0.07 & 0.26 \\
\hline Higher Education & 0.19 & 0.39 & 0.15 & 0.35 \\
\hline Immigrant to Germany since 1948 & 0.20 & 0.40 & 0.16 & 0.37 \\
\hline Years since Migration & 4.15 & 9.29 & 3.46 & 8.70 \\
\hline Managers & 0.06 & 0.24 & 0.02 & 0.15 \\
\hline Professionals & 0.17 & 0.38 & 0.12 & 0.33 \\
\hline Technicians & 0.16 & 0.37 & 0.28 & 0.45 \\
\hline Clerks & 0.08 & 0.27 & 0.20 & 0.40 \\
\hline Service \& sales workers & 0.04 & 0.20 & 0.19 & 0.39 \\
\hline Agricultural \& fishery & 0.01 & 0.08 & 0.01 & 0.08 \\
\hline Craft \& related workers & 0.28 & 0.45 & 0.04 & 0.20 \\
\hline Operators \& assemblers & 0.13 & 0.34 & 0.04 & 0.20 \\
\hline Elementary occupations (ref) & 0.06 & 0.24 & 0.10 & 0.30 \\
\hline Agriculture & 0.01 & 0.10 & 0.01 & 0.07 \\
\hline Energy & 0.02 & 0.12 & 0.00 & 0.07 \\
\hline Mining & 0.01 & 0.09 & 0.00 & 0.02 \\
\hline Manufacturing & 0.30 & 0.46 & 0.17 & 0.37 \\
\hline Construction & 0.22 & 0.41 & 0.05 & 0.22 \\
\hline Trade & 0.10 & 0.30 & 0.19 & 0.40 \\
\hline Transport & 0.06 & 0.25 & 0.03 & 0.18 \\
\hline Finance & 0.04 & 0.19 & 0.05 & 0.22 \\
\hline Service (ref) & 0.25 & 0.43 & 0.50 & 0.50 \\
\hline Age & 40.61 & 11.55 & 39.82 & 11.47 \\
\hline Married & 0.60 & 0.49 & 0.56 & 0.50 \\
\hline Children under age 18 & 0.67 & 1.00 & 0.51 & 0.85 \\
\hline Number of observations & 85928 & 85928 & 69476 & 69476 \\
\hline
\end{tabular}

Notes: Based on 1986-2011 German Socio-Economic Panel (G-SOEP) data. STD represents standard deviation. 
Table 2: Coefficient Estimates of the Wage Equations

\begin{tabular}{|c|c|c|c|c|}
\hline & \multicolumn{2}{|c|}{ Male } & \multicolumn{2}{|c|}{ Female } \\
\hline & Coef. & S.E. & Coef. & S.E. \\
\hline \multicolumn{5}{|l|}{ Time varying covariates } \\
\hline Exp & $0.054 *$ & $(0.001)$ & $0.048 *$ & $(0.001)$ \\
\hline Exp squared/100 & $-0.091 *$ & $(0.002)$ & $-0.092 *$ & $(0.002)$ \\
\hline Years since Migration & $-0.002 *$ & $(0.001)$ & $0.002 \dagger$ & $(0.001)$ \\
\hline Managers & $0.083 *$ & $(0.011)$ & $0.185 *$ & $(0.017)$ \\
\hline Professionals & $0.124 *$ & $(0.010)$ & $0.223 *$ & $(0.013)$ \\
\hline Technicians & $0.042 *$ & $(0.009)$ & $0.110 *$ & $(0.009)$ \\
\hline Clerks & -0.003 & $(0.010)$ & $0.081 *$ & $(0.010)$ \\
\hline Service \& sales workers & $-0.049 *$ & $(0.013)$ & 0.007 & $(0.009)$ \\
\hline Agricultural \& fishery & $-0.079 *$ & $(0.031)$ & -0.050 & $(0.045)$ \\
\hline Craft \& related workers & $-0.057 *$ & $(0.008)$ & 0.005 & $(0.014)$ \\
\hline Operators \& assemblers & $-0.019 \dagger$ & $(0.009)$ & 0.013 & $(0.014)$ \\
\hline Agriculture & $-0.068 *$ & $(0.026)$ & -0.040 & $(0.035)$ \\
\hline Energy & $0.039 \ddagger$ & $(0.022)$ & $0.136 *$ & $(0.041)$ \\
\hline Mining & $0.073 *$ & $(0.028)$ & $0.458 *$ & $(0.134)$ \\
\hline Manufacturing & $0.018 \dagger$ & $(0.008)$ & $0.016 \ddagger$ & $(0.009)$ \\
\hline Construction & 0.008 & $(0.008)$ & $0.043 *$ & $(0.013)$ \\
\hline Trade & $-0.049 *$ & $(0.009)$ & $-0.032 *$ & $(0.008)$ \\
\hline Transport & $-0.038 *$ & $(0.011)$ & $0.049 *$ & $(0.017)$ \\
\hline Finance & $0.048 \dagger$ & $(0.019)$ & $0.096 *$ & $(0.018)$ \\
\hline \multicolumn{5}{|l|}{ Time averaged means } \\
\hline Less than primary & $-0.046 *$ & $(0.008)$ & $-0.044 *$ & $(0.010)$ \\
\hline Primary & $-0.051 *$ & $(0.004)$ & $-0.050 *$ & $(0.005)$ \\
\hline Vocational Plus Abi & $0.029 *$ & $(0.006)$ & $0.050 *$ & $(0.006)$ \\
\hline Higher Vocational & $0.040 *$ & $(0.005)$ & $0.063 *$ & $(0.007)$ \\
\hline Higher Education & $0.164 *$ & $(0.005)$ & $0.136 *$ & $(0.006)$ \\
\hline Immigrant to Germany since 1948 & $-0.124 *$ & $(0.008)$ & $-0.099 *$ & $(0.011)$ \\
\hline $\operatorname{Exp}(\mathrm{m})$ & $-0.038 *$ & $(0.001)$ & $-0.027 *$ & $(0.001)$ \\
\hline Exp squared/100 (m) & $0.055 *$ & $(0.002)$ & $0.061 *$ & $(0.003)$ \\
\hline Years since migration $(\mathrm{m})$ & $0.007 *$ & $(0.001)$ & $0.002 \dagger$ & $(0.001)$ \\
\hline Managers (m) & $0.458 *$ & $(0.016)$ & $0.501 *$ & $(0.026)$ \\
\hline Professionals (m) & $0.311 *$ & $(0.014)$ & $0.485 *$ & $(0.019)$ \\
\hline Technicians (m) & $0.258 *$ & $(0.013)$ & $0.327 *$ & $(0.015)$ \\
\hline Clerks (m) & $0.157 *$ & $(0.015)$ & $0.208 *$ & $(0.016)$ \\
\hline Service \& sales workers (m) & $0.104 *$ & $(0.018)$ & $0.129 *$ & $(0.016)$ \\
\hline Agricultural \& fishery (m) & $0.168 *$ & $(0.043)$ & $0.251 *$ & $(0.060)$ \\
\hline Craft \& related workers $(\mathrm{m})$ & $0.125 *$ & $(0.012)$ & $0.129 *$ & $(0.023)$ \\
\hline Operators \& assemblers (m) & $0.063 *$ & $(0.013)$ & 0.034 & $(0.023)$ \\
\hline Agriculture (m) & $-0.176 *$ & $(0.035)$ & $-0.185 *$ & $(0.056)$ \\
\hline Energy $(\mathrm{m})$ & $0.124 *$ & $(0.027)$ & $0.121 \dagger$ & $(0.055)$ \\
\hline Mining $(\mathrm{m})$ & $0.108 *$ & $(0.037)$ & -0.040 & $(0.241)$ \\
\hline Manufacturing (m) & $0.117 *$ & $(0.009)$ & $0.089 *$ & $(0.012)$ \\
\hline Construction (m) & $0.129 *$ & $(0.010)$ & $0.113 *$ & $(0.018)$ \\
\hline Trade $(\mathrm{m})$ & $-0.114 *$ & $(0.012)$ & $-0.111 *$ & $(0.011)$ \\
\hline Transport (m) & $0.045 *$ & $(0.014)$ & $0.049 \dagger$ & $(0.023)$ \\
\hline Finance $(\mathrm{m})$ & $0.196 *$ & $(0.022)$ & $0.122 *$ & $(0.022)$ \\
\hline Age $(\mathrm{m})$ & $0.046 *$ & $(0.002)$ & $0.046 *$ & $(0.002)$ \\
\hline Age squared/100 (m) & $-0.042 *$ & $(0.002)$ & $-0.054 *$ & $(0.002)$ \\
\hline Married (m) & $0.084 *$ & $(0.004)$ & $-0.023 *$ & $(0.005)$ \\
\hline Children under age $18(\mathrm{~m})$ & $0.018 *$ & $(0.002)$ & $0.005 \ddagger$ & $(0.003)$ \\
\hline \multicolumn{5}{|l|}{ Inverse Mills Ratios } \\
\hline IMR & $-0.195 *$ & $(0.035)$ & 0.009 & $(0.025)$ \\
\hline
\end{tabular}


Table 2 - Continued from previous page

\begin{tabular}{lcccc}
\hline & \multicolumn{2}{c}{ Male } & \multicolumn{2}{c}{ Female } \\
& Coef. & S.E. & Coef. & S.E. \\
\hline $\mathrm{IMR} \times 1987$ & -0.065 & $(0.047)$ & -0.007 & $(0.031)$ \\
$\mathrm{IMR} \times 1988$ & 0.015 & $(0.047)$ & 0.029 & $(0.031)$ \\
$\mathrm{IMR} \times 1989$ & $0.139 *$ & $(0.044)$ & $0.053 \ddagger$ & $(0.029)$ \\
$\mathrm{IMR} \times 1990$ & $0.151 *$ & $(0.045)$ & $0.077 *$ & $(0.029)$ \\
$\mathrm{IMR} \times 1991$ & $0.116 *$ & $(0.044)$ & $0.065 \dagger$ & $(0.029)$ \\
$\mathrm{IMR} \times 1992$ & $0.204 *$ & $(0.044)$ & $0.139 *$ & $(0.029)$ \\
$\mathrm{IMR} \times 1993$ & $0.280 *$ & $(0.044)$ & $0.139 *$ & $(0.029)$ \\
$\mathrm{IMR} \times 1994$ & $0.252 *$ & $(0.044)$ & $0.129 *$ & $(0.029)$ \\
$\mathrm{IMR} \times 1995$ & $0.187 *$ & $(0.044)$ & $0.084 *$ & $(0.029)$ \\
$\mathrm{IMR} \times 1996$ & $0.171 *$ & $(0.044)$ & $0.140 *$ & $(0.030)$ \\
$\mathrm{IMR} \times 1997$ & $0.175 *$ & $(0.045)$ & $0.067 \dagger$ & $(0.029)$ \\
$\mathrm{IMR} \times 1998$ & $0.162 *$ & $(0.043)$ & $0.087 *$ & $(0.028)$ \\
$\mathrm{IMR} \times 1999$ & $0.147 *$ & $(0.043)$ & $0.095 *$ & $(0.029)$ \\
$\mathrm{IMR} \times 2000$ & $0.153 *$ & $(0.039)$ & $0.085 *$ & $(0.026)$ \\
$\mathrm{IMR} \times 2001$ & $0.108 *$ & $(0.040)$ & $0.059 \dagger$ & $(0.026)$ \\
$\mathrm{IMR} \times 2002$ & $0.177 *$ & $(0.039)$ & $0.103 *$ & $(0.027)$ \\
$\mathrm{IMR} \times 2003$ & $0.218 *$ & $(0.041)$ & $0.077 *$ & $(0.027)$ \\
$\mathrm{IMR} \times 2004$ & $0.114 *$ & $(0.042)$ & $0.054 \dagger$ & $(0.027)$ \\
$\mathrm{IMR} \times 2005$ & $-0.067 \ddagger$ & $(0.043)$ & -0.006 & $(0.028)$ \\
$\mathrm{IMR} \times 2006$ & $-0.087 \dagger$ & $(0.044)$ & $-0.100 *$ & $(0.029)$ \\
$\mathrm{IMR} \times 2007$ & & & &
\end{tabular}

Notes: Based on 1986-2011 German Socio-Economic Panel (G-SOEP) data.; *, $\dagger$ and $\ddagger$ indicate significance at 1, 5 and 10 percent levels respectively.; IMR $\times$ Year indicates the interactions between lambda terms and year dummies. 


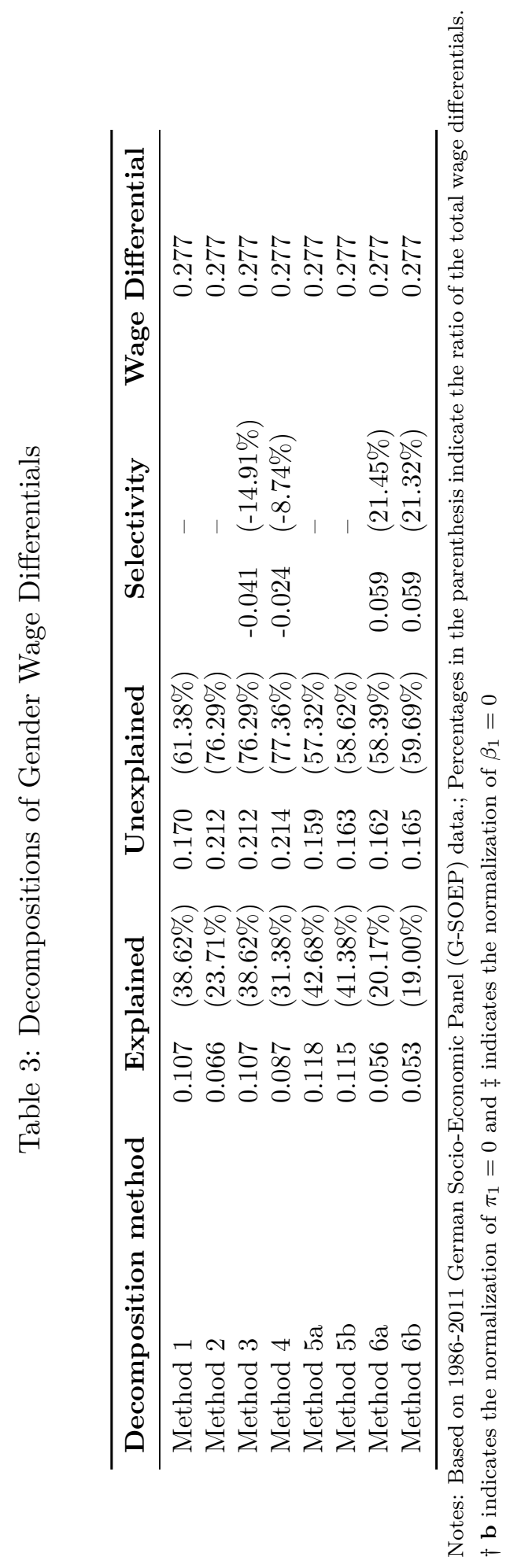

